\title{
Theoretical Study of the Absorption Spectrum and the Thermochemistry of the $\mathrm{CF}_{3} \mathrm{OSO}_{3}$ Radical
}

\author{
Carlos J. Cobos and Adela E. Croce \\ Instituto de Investigaciones Fisicoquímicas Teóricas y Aplicadas (INIFTA), Departamento de \\ Química. Facultad de Ciencias Exactas. Universidad Nacional de La Plata. CCT La Plata-CONICET. \\ Casilla de Correo 16. Sucursal 4, (1900) La Plata, Argentina
}

Reprint requests to A. E. C.: E-mail: acroce@ inifta.unlp.edu.ar

Z. Naturforsch. 65a, 720 -724 (2010); received June 29, 2009 / revised November 23, 2009

\begin{abstract}
The UV-visible absorption spectrum of the recently reported $\mathrm{CF}_{3} \mathrm{OSO}_{3}$ radical has been studied by using the time-dependent generalization of the density functional theory (TDDFT). For this a set of eleven hybrid functionals combined with the $6-311+\mathrm{G}(3 \mathrm{df})$ basis set were employed. The main features of the three experimental absorption bands of $\mathrm{CF}_{3} \mathrm{OSO}_{3}$ recorded over the $220-530 \mathrm{~nm}$ range are well reproduced by the calculations. A dissociation enthalpy for the $\mathrm{CF}_{3} \mathrm{O}_{-} \mathrm{SO}_{3}$ bond of $19.1 \mathrm{kcal}$ $\mathrm{mol}^{-1}$ is predicted at the BAC-G3MP2//B3LYP/6-311+G(3df) level of theory.
\end{abstract}

Key words: $\mathrm{CF}_{3} \mathrm{OSO}_{3}$ : Absorption Spectra: Bond Dissociation Energy: Time-Dependent Density Functional Theory

\section{Introduction}

Spectroscopic and theoretical studies of the novel $\mathrm{CF}_{3} \mathrm{OSO}_{3}$ radical have been recently reported [1]. The IR and UV-visible spectra recorded in cryogenic matrices combined with density functional theory (DFT) calculations have provided a conclusive proof for the existence of this species. The absorption spectrum exhibits a strongly structured main band situated between the origin, located at $526.8 \mathrm{~nm}$ and $390 \mathrm{~nm}$, and two additional weaker UV bands picked at 305 and $238 \mathrm{~nm}$. The first band resembles in shape the well-known visible band of the related $\mathrm{FSO}_{3}$ radical [2-6], while the other bands appear to support the new intense band of $275 \mathrm{~nm}$ recently reported for $\mathrm{FSO}_{3}$ [6]. As in this last study, a detailed TDDFT analysis of the UV and visible $\mathrm{CF}_{3} \mathrm{OSO}_{3}$ spectra ( $220-530 \mathrm{~nm}$ ) has been performed in this work. In addition, the $\mathrm{CF}_{3} \mathrm{OSO}_{3}$ thermal stability has been explored by using high-level ab initio quantum chemical calculations.

\section{Computational Methods}

The TDDFT theory stands as a promising alternative to cumbersome many-body approaches to the calculation of the electronic excitation [7]. This approach has emerged as a very successful framework to reproduce remarkably well experimental transition energies of valence excited states which can be described by combinations of single one electron transitions [8]. In particular, the TDDFT gives a well-balanced description of open-shell systems such as excited states of radicals [9]. However, the real exchange-correlation functional is unknown and the best DFT model is difficult to establish a priori [10]. For this reason, different formulations are usually employed and tested against experiments. Here, the hybrid functionals B3P86, B3PW91, B3LYP, B1B95, B1LYP, mPW0, B98, B97-1, B972, PBE0, and X3LYP as implemented in the Gaussian 03 program package were employed [11]. The large $6-311+G(3 \mathrm{df})$ triple split valence basis set was employed in all cases. The 81 valence electrons of $\mathrm{CF}_{3} \mathrm{OSO}_{3}$ were accommodated in molecular orbitals which comprise 359 basis functions employing 536 primitive Gaussians. Geometry optimizations without symmetry constraints were carried out using analytical gradient methods. For all DFT methods, real vibrational frequencies were obtained assuring that computed structures correspond to stable compounds. To cover the experimental spectrum, the first eleven electronic states of $\mathrm{CF}_{3} \mathrm{OSO}_{3}$ were calculated.

\section{Absorption Spectra of $\mathrm{CF}_{3} \mathrm{OSO}_{3}$}

Table 1 shows the calculated vertical excitation energies $E$ and oscillator strengths $f$ for the eight more 
Table 1. Vertical excitation energies (in $\mathrm{eV}$ ) and oscillator strengths for the more significant electronic states of $\mathrm{CF}_{3} \mathrm{OSO}_{3}$ calculated using different functionals with the $6-311+\mathrm{G}(3 \mathrm{df})$ basis set.

\begin{tabular}{|c|c|c|c|c|c|c|c|c|c|}
\hline \multirow{2}{*}{$\begin{array}{l}\text { Level of } \\
\text { theory }\end{array}$} & \multirow[t]{2}{*}{ Property } & \multicolumn{8}{|c|}{ State } \\
\hline & & 1 & 2 & 3 & 4 & 5 & 6 & 7 & 8 \\
\hline \multirow[t]{2}{*}{$\overline{\text { B3P86 }}$} & $E$ & 2.56 & 2.74 & 2.77 & 3.40 & 4.23 & 4.99 & 5.13 & 5.75 \\
\hline & $f$ & 0.0136 & 0.0227 & 0.0039 & 0.0043 & 0.0047 & 0.0039 & 0.0042 & 0.0131 \\
\hline \multirow[t]{2}{*}{ B3PW91 } & $E$ & 2.591 & 2.78 & 2.88 & 3.49 & 4.32 & 5.08 & 5.22 & 5.83 \\
\hline & $f$ & 0.0117 & 0.0184 & 0.0111 & 0.0037 & 0.0042 & 0.0032 & 0.0035 & 0.0105 \\
\hline \multirow[t]{2}{*}{ B3LYP } & $E$ & 2.56 & 2.74 & 2.84 & 3.43 & 4.26 & 5.03 & 5.17 & 5.76 \\
\hline & $f$ & 0.0120 & 0.0152 & 0.0141 & 0.0034 & 0.0041 & 0.0031 & 0.0051 & 0.0111 \\
\hline \multirow[t]{2}{*}{ B1B95 } & $E$ & 2.56 & 2.77 & 2.92 & 3.62 & 4.49 & 5.26 & 5.46 & 5.95 \\
\hline & $f$ & 0.0108 & 0.0161 & 0.0125 & 0.0046 & 0.0061 & 0.0047 & 0.0085 & 0.0104 \\
\hline \multirow[t]{2}{*}{ B1LYP } & $E$ & 2.65 & 2.79 & 3.09 & 3.83 & 4.21 & 5.51 & 5.68 & 6.16 \\
\hline & $f$ & 0.0128 & 0.0272 & 0.0053 & 0.0036 & 0.0058 & 0.0043 & 0.0107 & 0.0094 \\
\hline \multirow[t]{2}{*}{$\mathrm{mPW}$} & $E$ & 2.71 & 2.86 & 3.18 & 3.93 & 4.80 & 5.58 & 5.76 & 6.26 \\
\hline & $f$ & 0.0127 & 0.0276 & 0.0052 & 0.0039 & 0.0062 & 0.0043 & 0.0110 & 0.0099 \\
\hline \multirow[t]{2}{*}{ B98 } & $E$ & 2.59 & 2.78 & 2.91 & 3.58 & 4.43 & 5.22 & 5.37 & 5.92 \\
\hline & $f$ & 0.0120 & 0.0207 & 0.0097 & 0.0038 & 0.0051 & 0.0039 & 0.0066 & 0.0113 \\
\hline \multirow[t]{2}{*}{ B97-1 } & $E$ & 2.57 & 2.76 & 2.86 & 3.49 & 4.33 & 5.10 & 5.24 & 5.83 \\
\hline & $f$ & 0.0118 & 0.0148 & 0.0145 & 0.0037 & 0.0045 & 0.0033 & 0.0054 & 0.0110 \\
\hline \multirow[t]{2}{*}{ B97-2 } & $E$ & 2.61 & 2.79 & 2.93 & 3.57 & 4.41 & 5.18 & 5.32 & 5.91 \\
\hline & $f$ & 0.0114 & 0.0183 & 0.0119 & 0.0038 & 0.0047 & 0.0033 & 0.0059 & 0.0105 \\
\hline \multirow[t]{2}{*}{ PBE0 } & $E$ & 2.70 & 2.86 & 3.16 & 3.90 & 4.77 & 5.55 & 5.74 & 6.24 \\
\hline & $f$ & 0.0122 & 0.0272 & 0.0055 & 0.0039 & 0.0060 & 0.0042 & 0.0106 & 0.0098 \\
\hline \multirow[t]{2}{*}{ X3LYP } & $E$ & 2.58 & 2.76 & 2.89 & 3.55 & 4.39 & 5.18 & 5.33 & 5.87 \\
\hline & $f$ & 0.0122 & 0.0223 & 0.0080 & 0.0035 & 0.0047 & 0.0038 & 0.0065 & 0.0114 \\
\hline
\end{tabular}

relevant doublet-doublet valence electronic transitions of $\mathrm{CF}_{3} \mathrm{OSO}_{3}$. The oscillator strength depends on electronic, Frank-Condon, and spin factors, which reduce the unity maximum value expected for a totally allowed transition, and provides information on the intensity of the experimental band. In spite of the different combinations of exchange and correlation functionals a similar trend is observed. Thus, no approach can be definitely attributed superior to the rest. For this reason, to compare with experiments, the computed data listed in Table 1 were averaged. In this way, the resulting values for $E$ are $2.61 \pm 0.05,2.78 \pm 0.04$, $2.95 \pm 0.13,3.62 \pm 0.19,4.42 \pm 0.20,5.24 \pm 0.21$, $5.40 \pm 0.23$, and $5.95 \pm 0.18 \mathrm{eV}$, while the associated $f$ values are $0.0121 \pm 0.0007,0.0210 \pm 0.0049,0.0092 \pm$ $0.0039,0.0038 \pm 0.0003,0.0051 \pm 0.0008,0.0038 \pm$ $0.0005,0.0071 \pm 0.0027$, and $0.0108 \pm 0.0010$. It can be observed that the estimated standard deviations are small for $E, 1-5 \%$, and significantly larger for $f, 6-$ $40 \%$. The stated limits for $E$ are similar to those derived for the $\mathrm{FSO}_{3}$ radical, while the deviations are much larger for $f$, due to the fact that the respective values are smaller [6]. An analysis in terms of the individual DFT methods shows that the B98 method gives the best match to the average values. In fact, this functional leads to deviations of only $0.02 \mathrm{eV}$ and 0.0002 units from the above $E$ and $f$ values. The calculated excitation energies of 2.61, 2.78 and $2.95 \mathrm{eV}$ lie within the strongest experimental band localized between 2.3 and $3.2 \mathrm{eV}$. The values of 3.62 and $4.42 \mathrm{eV}$ correspond to the weakest observed band centered at $4.1 \mathrm{eV}$, while the transitions located at 5.24 and $5.40 \mathrm{eV}$ correspond to the measured band of $5.2 \mathrm{eV}$.

In order to perform a better comparison between the experiments and the theoretical predictions, a modelling of the spectrum was carried out. To this end, the absorption coefficient of each electronic transition was represented by individual Gaussian functions: $\varepsilon_{i}=\varepsilon_{\max , i} \exp \left[-\left(1 / 2 \sigma_{i}^{2}\right)\left(E_{i}-E_{\max , i}\right)^{2}\right]$. Following a procedure similar to that described in [6], the decadic absorption coefficient $\varepsilon$ was derived by relating the maximum absorption coefficient $\varepsilon_{\max }$ with $f$ and with the full width $\sigma$ of the band at $1 / \mathrm{e}$ height:

$\varepsilon \simeq 1.15 \times 10^{4} \sum_{i=1}^{\infty}\left(f_{i} / \sigma_{i}\right) \exp \left[-\left(1 / 2 \sigma_{i}^{2}\right)\left(E_{i}-E_{\max , i}\right)^{2}\right]$.

This expression allows to obtain $\varepsilon$ (in $\mathrm{M}^{-1} \mathrm{~cm}^{-1}$ ) as a function of the calculated $E_{i}$ and $f_{i}$ values. In the absence of a theoretical basis, as frequently, $\sigma$ was used as a fitted parameter.

Due to the fact that the $\mathrm{CF}_{3} \mathrm{OSO}_{3}$ concentration and the matrix thickness (the optical pathway) are un- 


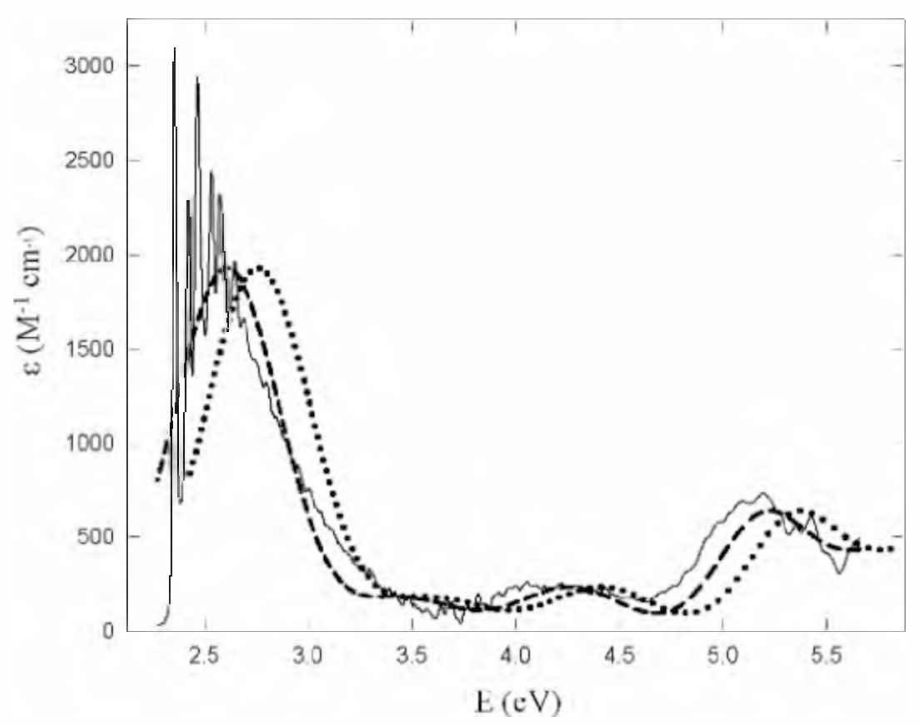

Fig. 1. Comparison between the experimental and computed UV-visible spectra of $\mathrm{CF}_{3} \mathrm{OSO}_{3}$. (-): [1]: $(\cdots)$ : TDDFT calculations (see text): (-- -): TDDFT calculations shifted by $-0.15 \mathrm{eV}$ (see text). known, the spectrum has been reported in absorbance units [1]. For comparison with the theoretical predictions, the absorbance values were appropriately scaled to transform to absorption coefficients $\varepsilon$. Figure 1 shows the spectra obtained by dividing the experimental absorption data by the factor $1.31 \times 10^{-4} \mathrm{M} \mathrm{cm}$, together with the spectrum computed using (1) with the above given set of average $E$ and $f$ values and a single value of $\sigma=0.21 \mathrm{eV}$ (i. e. assuming a unique decay rate constant for all of the excited states involved). Even though the whole shape of the spectrum is reproduced, it is clear that the energies of the electronic transitions are somewhat overestimated. By contrast, similar TDDFT calculations lead to a very good agreement in position $(470 \mathrm{~nm}$ ) and intensity (as indicated by the very similar experimental and computed $f$ values) for the strongest absorption band $\left({ }^{2} \mathrm{E}-\mathrm{X}^{2} \mathrm{~A}_{2}\right)$ of the $\mathrm{FSO}_{3}$ radical in the gas phase [6]. In order to match the experimental and theoretical UV band of $\mathrm{CF}_{3} \mathrm{OSO}_{3}$, all excitation energies were equally shifted by $-0.15 \mathrm{eV}$, as usual in IR spectroscopy. It should be noted that typical TD-B3LYP deviations for excitation energies lie normally within $0.3-0.4 \mathrm{eV}$ with respect to experiments [12]. This correction implies a red-shift of the theoretical visible band by about $25 \mathrm{~nm}$ and of the UV bands by about $8 \mathrm{~nm}$. As Figure 1 shows, the present calculations reproduce reasonably well the global contour of the visible and UV bands. As before, we used $\sigma=0.21 \mathrm{eV}$ and a scaling factor for the experimental data of $1.31 \times 10^{-4} \mathrm{M} \mathrm{cm}$. A better agreement between experiments and theory could be clearly ex- pected employing different $\sigma$ values for the different transitions. However, no significant improvement was observed by using in (1) the fitted $\sigma$ values of 0.22 (for transitions $i=1-3$ ), 0.25 (for $i=4,5$ ), 0.20 (for $i=6,7$ ), and $0.29 \mathrm{eV}$ (for $i=8$ ), and a scaling constant of $1.34 \times 10^{-4} \mathrm{M} \mathrm{cm}$.

The present simulations allow to transform the experimental $\mathrm{CF}_{3} \mathrm{OSO}_{3}$ absorbance data on an absolute basis. In this way, the absorption coefficients estimated from the experimental data at about the center of the first band of $480 \mathrm{~nm}(2.58 \mathrm{eV})$ and at the band maxima of $305 \mathrm{~nm}(4.07 \mathrm{eV})$ and $238 \mathrm{~nm}(5.21 \mathrm{eV})$ [1] are 2180,240 , and $690 \mathrm{M}^{-1} \mathrm{~cm}^{-1}$, respectively. The first $\varepsilon$ value is a factor of two larger than the estimated for $\mathrm{CF}_{3} \mathrm{OSO}_{3}$ in [1]. In addition, it is also significantly larger than the one measured for $\mathrm{FSO}_{3}$ at the center of the band located near $470 \mathrm{~nm}$ of $1160 \mathrm{M}^{-1} \mathrm{~cm}^{-1}$ [5].

\section{Thermochemistry of $\mathrm{CF}_{3} \mathrm{OSO}_{3}$}

The knowledge of the energetic changes associated with molecular bonds making and breaking is of crucial importance in many practical fields such as atmospheric and combustion chemistry [13-14]. As a first guess, we derived the dissociation enthalpy for the $\mathrm{CF}_{3} \mathrm{O}-\mathrm{SO}_{3}$ bond from the computed total energies (corrected by thermal contributions) of $\mathrm{CF}_{3} \mathrm{OSO}_{3}, \mathrm{CF}_{3} \mathrm{O}$, and $\mathrm{SO}_{3}$ molecules. The value obtained for this weakest $\mathrm{CF}_{3} \mathrm{OSO}_{3}$ bond at the composite G3MP2//B3LYP/6-311+G(3df) ab initio level is $\Delta H_{298}=14.6 \mathrm{kcal} \mathrm{mol}^{-1}[15]$ 
Further calculations based on a computed G3MP2// B3LYP/6-311+G(3df) standard enthalpy of formation for $\mathrm{CF}_{3} \mathrm{OSO}_{3}$ at $298 \mathrm{~K}$ corrected by bond additivity [16] were performed. These bond additivity corrections (BAC) account for systematic errors due to deficiencies in the treatment of the interaction electron correlation, molecular electronic structure, and electron pairing. These corrections reduce the estimated G3MP2//B3LYP/6-311+G(3df) enthalpy of formation of $-258.4 \mathrm{kcal} \mathrm{mol}^{-1}$ to the BAC-G3MP2//B3LYP/6$311+\mathrm{G}(3 \mathrm{df})$ value of $-265.5 \mathrm{kcal} \mathrm{mol}^{-1}$. Using this last value combined with recommended enthalpies of formation for $\mathrm{CF}_{3} \mathrm{O}$ and $\mathrm{SO}_{3}$ of $-151.8 \pm 1.7$ and $-94.62 \pm 0.17 \mathrm{kcal} \mathrm{mol}^{-1}$ [12] leads to an enthalpy change of $\Delta H_{298}=19.1 \pm 2 \mathrm{kcal} \mathrm{mol}^{-1}$ for the $\mathrm{CF}_{3} \mathrm{OSO}_{3} \rightarrow \mathrm{CF}_{3} \mathrm{O}+\mathrm{SO}_{3}$ process. The stated errors account for both, experimental and theoretical uncertainties $[13,15,16]$. This enthalpy change is higher than the lower limit computed at the B3LYP/6$311+\mathrm{G}(3 \mathrm{df})$ level of $16.7 \mathrm{kcal} \mathrm{mol}^{-1}$ and supports the stability predicted for the $\mathrm{CF}_{3} \mathrm{OSO}_{3}$ radical [1].

[1] S. von Ahsen and J. S. Francisco. J. Phys. Chem. A. 109. $9193(2005)$.

[2] E. Castellano, R. Gatti, J.E. Sicre, and H. J. Schumacher, Z. Phys. Chem. NF, 42, 174 (1964).

[3] G. W. King, D. P. Santry, and C. H. Warren, J. Mol. Spectrosc. 32. 108 (1969).

[4] A.E. Croce, J. Photochem. Photobiol. A: Chem. 51. 293 (1990).

[5] C. J. Cobos, A. E. Croce, and E. Castellano. J. Photochem. Photobiol. A: Chem. 84, 101 (1994).

[6] C. J. Cobos and A. E. Croce. Z. Phys. Chem. 321, 897 (2007).

[7] G. Onida, L. Reining, and A. Rubio, Rev. Mod. Phys. 74, 601 (2002).

[8] K. B. Wiberg, R. E. Stratman, and M. J. Frisch, Chem. Phys. Lett. 297. 60 (1998).

[9] S. Hirata and M. Head-Gordon, Chem. Phys. Lett. 302, 375 (1999).

[10] P. Hohenberg and W. Kohn. Phys. Rev. B. 136. 864 (1964).

[11] Gaussian 03, Revision D.01, M. J. Frisch, G. W. Trucks, H. B. Schlegel, G.E. Scuseria, M. A. Robb, J. R. Cheeseman, J. A. Montgomery, Jr., T. Vreven, K. N. Kudin. J.C. Burant. J. M. Millam. S. S. Iyengar. J. Tomasi, V. Barone, B. Mennucci, M. Cossi. G. Scalmani. N. Rega. G. A. Petersson. H. Nakatsuji, M. Hada, M. Ehara, K. Toyota, R. Fukuda, J. Hasegawa, M. Ishida, T. Nakajima, Y. Honda,

\section{Conclusion}

The present theoretical study indicates that the TDDFT methods are able to explain reasonably well the features of the UV-visible spectrum of $\mathrm{CF}_{3} \mathrm{OSO}_{3}$. This fact in combination with the here confirmed thermal stability towards the dissociation to $\mathrm{CF}_{3} \mathrm{O}$ and $\mathrm{SO}_{3}$ radicals reinforces the existence of this interesting species, and supports the suggested potential participation of this species in the atmospheric chemistry mechanisms.

\section{Acknowledgements}

This work was supported by the Universidad Nacional de La Plata, the Consejo Nacional de Investigaciones Científicas y Técnicas (CONICET), the Agencia Nacional de Promoción Científica y Tecnológica and the Max Planck Institute for Biophysical Chemistry (Karl Friedrich Bonhoeffer Institute), Götlingen, through the 'Partner Group for Chlorofluorocarbons in the Atmosphere' with Prof. Dr. Jürgen Troe.

O. Kitao. H. Nakai. M. Klene. X. Li. J. E. Knox. H. P. Hratchian, J. B. Cross, V. Bakken, C. Adamo, J. Jaramillo, R. Gomperts, R. E. Stratmann, O. Yazyev, A. J. Austin. R. Cammi, C. Pomelli, J. W. Ochterski. P. Y. Ayala, K. Morokuma, G. A. Voth, P. Salvador, J. J. Dannenberg. V. G. Zakrzewski. S. Dapprich. A. D. Daniels, M. C. Strain, O. Farkas, D. K. Malick, A. D. Rabuck, K. Raghavachari, J. B. Foresman, J. V. Ortiz. Q. Cui, A. G. Baboul, S. Clifford. J. Cioslowski. B. B. Stefanov, G. Liu, A. Liashenko, P. Piskorz, I. Komaromi. R. L. Martin. D. J. Fox. T. Keith. M. A. AlLaham, C. Y. Peng, A. Nanayakkara, M. Challacombe, P. M. W. Gill, B. Johnson, W. Chen. M. W. Wong. C. Gonzalez, J. A. Pople, Gaussian, Inc., Wallingford CT, 2004.

[12] S. Grimme, in: Reviews on Computational Chemistry (Eds. K. B. Lipkowitz, R. Larter, T. R. Cundari), WileyVCH, John Wiley \& Sons, Inc., Volume 20, 2004, p. 153.

[13] S. P. Sander, R. R. Friedl, D. M. Golden, M. J. Kurylo, G. K. Moortgat, P. H. Wine, A. R. Ravishankara. C. E. Kolb, M. J. Molina, B. J. Finlayson-Pitts, R. E. Huie, V.L. Orkin, Chemical Kinetics and Photochemical Data for Use in Atmospheric Studies: NASA/JPL Data Evaluation. JPL Publication 06-2 Evaluation No. 15: NASA: Pasadena. CA. November 20, 2006. http://jpldataeval.jpl.nasa.gov/i/a $/{ }_{i}$. 
[14] D. L. Baulch. C. T. Bowman, C. J. Cobos, R. A. Cox. [15] A. G. Baboul. L. A. Curtiss, and P. C. Redfern. J. Chem. Th. Just, J. A. Kerr, M. J. Pilling, D. Stocker, J. Troe, W. Tsang. J. Walker. and J. Warnatz. J. Phys. Chem. Phys. 110. 7650 (1999).

Ref. Data, 34, 757 (2005).

[16] B. Anantharaman and C. F. Melius. J. Phys. Chem. A. 109. 1734 (2005). 